\title{
Number Processing and Calculation in Brazilian Children Aged 7-12 Years
}

\author{
Flávia Heloísa Dos Santos ${ }^{1}$, Paulo Adilson Da Silva ${ }^{1}$, Fabiana Silva Ribeiro ${ }^{1}$, Ana Luiza Ribeiro \\ Pereira Dias ${ }^{1}$, Michele Cândida Frigério ${ }^{1}$, Georges Dellatolas ${ }^{2}$, Michael von Aster ${ }^{3}$ \\ ${ }^{1}$ Universidade Estadual Paulista (Brazil) \\ ${ }^{2}$ Institut National de La Santé et de la Recherche Médicale (France) \\ ${ }^{3}$ University of Zurich (Switzerland)
}

\begin{abstract}
Numerical cognition is based on two components - number processing and calculation. Its development is influenced by biological, cognitive, educational, and cultural factors. The objectives of the present study were to: i) assess number processing and calculation in Brazilian children aged 7-12 years from public schools using the Zareki-R (Battery of neuropsychological tests for number processing and calculation in children, Revised; von Aster \& Dellatolas, 2006) in order to obtain normative data for Portuguese speakers; ii) identify how environment, age, and gender influences the development of these mathematical skills; iii) investigate the construct validity of the Zareki-R by the contrast with the Arithmetic subtest of WISC-III. The sample included 172 children, both genders, divided in two groups: urban $(N=119)$ and rural $(N=53)$ assessed by the Zareki-R. Rural children presented lower scores in one aspect of number processing; children aged 7-8 years demonstrated an inferior global score than older; boys presented a superior performance in both number processing and calculation. Construct validity of Zareki-R was demonstrated by high to moderate correlations with Arithmetic subtest of WISC-III. The Zareki-R therefore is a suitable instrument to assess the development of mathematical skills, which is influenced by factors such as environment, age, and gender.
\end{abstract}

Keywords: Zareki-R, mathematical skills, children, neuropsychological assessment, arithmetic.

La cognición numérica se basa en dos componentes: el procesamiento numérico y el cálculo. Su desarrollo está influenciado por factores biológicos, cognitivos, educativos, y culturales. Los objetivos del presente trabajo fueron: a) evaluar el procesamiento numérico y el cálculo en niños brasileños de entre 7-12 años de escuelas públicas utilizando el Zareki-R (batería de pruebas neuropsicológicas para el procesamiento numérico y el cálculo en niños, revisada por von Aster y Dellatolas, 2006) con el fin de obtener datos normativos para los hablantes de portugués, b) determinar cómo el medio ambiente, la edad y el género influyen en el desarrollo de estas habilidades matemáticas, y c) investigar la validez de constructo del Zareki-R en contraste con el subtest de Aritmética WISC-III. La muestra incluyó a 172 niños evaluados por el Zareki-R, niños de ambos sexos, divididos en dos grupos: urbano $(N=119)$ y rural $(N=53)$. Los niños de origen rural presentaron puntuaciones más bajas en un aspecto de procesamiento numérico, los niños de 7-8 años demostraron una puntuación inferior global que los mayores; los varones presentaron un rendimiento superior tanto en el procesamiento numérico como en el cálculo. La validez del constructo del Zareki-R fue demostrada por las correlaciones de alta a moderada con el subtest de Aritmética WISC-III. EI Zareki-R por lo tanto, es un instrumento adecuado para evaluar el desarrollo de habilidades matemáticas, que está influenciado por factores como el medio ambiente, la edad y el género.

Palabras clave: Zareki-R, habilidades matemáticas, niños, evaluación neuropsicológica, aritmética.

The study was developed at government schools in Assis and Ourinhos Cities, São Paulo State, Brazil. Results presented at the Experimental Psychology Society; EPS London Meeting. London: University College London, 2008.

We especially thank the parents and children for their participation and acknowledge the cooperation of the government schools at Assis and Ourinhos cities in São Paulo State. This project was supported by the International Cooperation Agreement between Fundação de Amparo à Pesquisa do Estado de São Paulo (FAPESP) and Institut National de La Santé et de la Recherche Médicale (INSERM) for cooperation between French and Brazilian researchers, case no 04/11.067-0. Financial support from FAPESP was also obtained for the granted students: Juliana Molina no 05/00595-8, Bruna Paschoalini no 05/00594-1, Rosana Satiko Kikuchi no 08/54971-2; Michele Cândida Frigério no 05/005935; Ana Luiza Ribeiro Pereira Dias n 2005/00592-9; Fabiana Silva Ribeiro no 08/54970-2; Paulo Adilson da Silva nº 05/60375-1.

Correspondence concerning this article should be addressed to Flávia Heloísa Dos Santos. Universidade Estadual Paulista, UNESP/Assis. Laboratório de Neuropsicologia. Programa de Pós-Graduação em Psicologia. Departamento de Psicologia Experimental e do Trabalho. Avenida Dom Antônio 2100 - cep 19806-900, Assis - SP, (Brazil). Phone: + 55-18-33025902. Fax: + 55-18-33025804; E-mail: flaviahs@assis.unesp.br 
Quantitative skills such as numerosity comprehension, ordinality, counting, and simple arithmetic develop during childhood (Cantlon, Platt, \& Brannon, 2009; Geary, 1995, 2000). In the primary school, children learn the base-10 system, different numerical representations; for example, transcoding from verbal code (twenty three) into Arabic code (23), and basic arithmetic (Geary, 2000). In the high school, the complexity of these processes increases and includes procedures of multiple steps, such as multiplication and division (Dehaene, 1997; Geary, Frensch, \& Wiley, 1993; O’Hare, 1999; Shalev, Manor, Amir, \& Gross-Tsur, 1993).

Gelman and Galistel (1978) assumed five counting principles listed below, three of them related to procedures rules, one related to the concept of countable items, and the last one is a combination of the four principles. The one-to-one-correspondance emphasizes the discrimination of a specific counting code for each object (Word, or Arabic or other form); the child must coordinate two processes: first each item to be counted must be transferred from the original category to the counting category (division), once counted the item must be annulated in order to not be counted twice (tagging). A typical strategy is pointing the items (visual code) while counting loudly (verbal code). The stable-order. Counting involves more than the ability to assign random tags to the items in an array. The counting marks must be organized in a stable manner, repeated in certain order. The cardinal principle. The last word in a sequence of numbers in general represents the total amount and the numerosity of the set. The comprehension of this concept depends on the principle of one-to-one, in other words, the principle of the stable order of correspondence develops after the child learn to tag items already counted and to name a set of items. The abstraction. The child must understand that the counting is independent of the object characteristics (toys, actions, sounds etc). The orderirrelevance. The child must learn that direction of counting is irrelevant (from left to the right and vice versa). The regular use of this principle emerges around 4-5 years old.

The calculation refers to the mathematical operations such as addition, subtraction, multiplication, and division; which require operational words (more, less, times, divide) and symbols $(+,-, \times$ or $\div)$, the retrieval of them and other arithmetic facts, and the arithmetic calculation procedure. On the other hand, number processing refers to comprehension of the numeric symbols associated with quantities, and number production in reading, writing and counting of numbers (McCloskey, Caramazza, \& Basili, 1985). The processing of the mathematical operations in practice depends on: a) the availability of cognitive number representations - visual Arabic, verbal, and analogue magnitude - (triple-code-model; Dehaene, 1997), that interact dynamically without the need of association between the numbers, and the quantities themselves (Dehaene \& Cohen, $2000)$; b) numerical skills that are based on a variety of modality-specific representations (e.g., visuospatial and verbal-auditory codes) in diverse number-processing tasks supporting the specific-integrated (encoding-complex) view of number processing (Campbell \& Clark, 1992).

According to Dehaene (1997), the number sense represents the innate ability to recognize, compare, add, and subtract small quantities, without the need of counting, in a mental number line, which is a spatially oriented representation of the quantities, that increases with age and experience, and account to large numerosities. The number sense capacity plays a fundamental role in mathematical competence (Dehaene, 2001; Iuculano, Tang, Hall, \& Butterworth, 2008). von Aster and Shalev (2007) described a four-step Developmental Model of Numerical Cognition, which considers that transitions from the pre-verbal period to adulthood, in both number skills and number sense, would culminate in the mental number line development. However, these changes demands more than an intact number system, they require experience, plasticity, and development of other skills such as visual imagery, language, and working memory.

On the other hand, socio-cultural, pedagogical, and linguistic factors may affect both number processing and calculation (Dellatolas, von Aster, Willardino-Braga, Meier, \& Deloche, 2000; Gross-Tsur, Manor, \& Shalev, 1996; Hein, Bzufka, \& Neumärker, 2000; Koumoula et al., 2004). In contrast, studies showed that working memory is culture free of socioeconomic status and environmental aspects (Engel, Santos, \& Gathercole, 2008; Koumoula et al., 2004; Santos \& Bueno, 2003; Santos, Mello, Bueno, \& Dellatolas, 2005).

Considering the complexity of the number processing and calculation cognitive systems, it is necessary to assess different aspects of the numerical domains separately, as for differential diagnosis and planning appropriate intervention strategies (von Aster, 2000). For this purpose, the ZAREKI (in German: Neuropsychologische Testbatterie für $\underline{\boldsymbol{Z} \boldsymbol{A}}$ hlenarbeitung und $\underline{\boldsymbol{R} \boldsymbol{E} t c h n e n ~ b e i ~} \underline{\boldsymbol{K}}$ ndern; von Aster, 2001), or NUCALC for the acronym in English (Neuropsychological Test Battery for $\underline{\text { Number Processing }}$ and $\underline{C a l c u l a t i o n}$ in $\underline{C}$ hildren), was developed. The preliminary version of this instrument was the EC301 battery (Batterie Standardisée D'evaluation du Calcul et $d u$ Traitement des Nombres) developed to assess numerical skills in adults (Dellatolas, Deloche, Basso, \& ClarosSalinas, 2001; Deloche, 1995; Deloche et al., 1995).

The ZAREKI was adapted for use in different countries and languages, for instance, German, French, and Greek (Dellatolas et al., 2000; Koumoula et al., 2004; von Aster, 2001; von Aster \& Dellatolas, 2006). Since secondary quantitative abilities are influenced by educational systems, which change across countries and generations (Dellatolas et al., 2000; Geary, 2000), it is important to assess mathematical skills using an equivalent instrument in different languages, which benefit cross-cultural studies. Many studies were accomplished with the ZAREKI: 
assessment of German and French children (von Aster, Deloche, Dellatolas, \& Meier, 1997), illiterates (Deloche, Souza, Willadino-Braga, \& Dellatolas, 1999), and patients with unilateral brain injury (Deloche, Dellatolas, Vendrell, \& Bergego, 1996; Deloche \& Willmes, 2000), etc.

Functional analysis indicated that the theoretical construct of the ZAREKI are oriented by Dehaene's Triple Code Model (Dehaene \& Cohen, 2000; von Aster, 2000) and is consistent with the four-step Developmental Model of Numerical Cognition (von Aster \& Shalev, 2007). The Figure 1 illustrates the relationship between the subtests of the ZAREKI with the three modules of representation (Verbal, Analog and Arabic codes) in contrast to the different combinations of the processing procedures overlapping them (input, internal transcoding, and output). The three modules are autonomous, interconnected and activated according to the particular needs of a given task and constitute a system for number processing and calculation. In this sense, according to the triple-code model, abilities such as approximation and number comparison depends on the analogue module, whereas abilities such as counting (in operations such as addition and subtraction, including the arithmetical fact retrieval) depends on the verbal module. Multi-digit operations and parity judgments rely on the visual Arabic module number form, in that numbers are represented by their Arabic code (von Aster, 2000). Moreover, the literature indicated that ZAREKI clearly differentiates and specifies the profile of mathematical skills in children being suitable for the diagnosis of Developmental Dyscalculia (DD) (von Aster, 2000; Shalev et al., 1993).

DD, also named as Specific Disorder of Arithmetical Skills (International Classification of Diseases, $10^{\text {th }}$ Edition [ICD-10], OMS, 1993) or Mathematics Disorder (Diagnostic and Statistical Manual of Mental Disorders, $4^{\text {th }}$ Edition, Text Revision [DSM-IV-TR], (APA, 2002), constitutes a specific difficulty in quantitative processing, which is expressed by difficulties to accomplish elementary operations such as addition, subtraction, multiplication, and division, not due to inefficient teaching or global intellectual disability (F81. 2, World Health Organization, 2005); and its diagnosis requires that these operations are assessed objectively by standardized tests (315.1, APA, 2002). The aetiology of DD is multi-factorial and includes genetic predisposition, neurological disturbances, environmental, and psychological factors (Shalev, 2004).

Hein et al. (2000) investigated the prevalence of arithmetic impairment in urban and rural children using the ZAREKI; they found a similar prevalence (around 6\%) between simple arithmetic and reading and spelling disorders. In their study children with DD showed lower scores than their counterparts; besides, the discrepancy between the mean scores and standard deviation suggested that boys performed better than girls. Koumoula et al. (2004) assessed Greek children with the same instrument, and identified that children from rural areas and low socioeconomic level presented inferior performance than the urban children in mental calculation, reading and writing of numbers, oral comparison of numbers, contextual estimation of quantities and problem solving. In Koumoula et al. (2004) the prevalence of children performing significantly worse in arithmetical skill was higher in rural than in urban students.

von Aster (2000) found differences associated with age and schooling on performance of German children. Moreover, boys performed better than girls in tasks of subtraction, oral comparison, and arithmetic problems; the gender difference was also observed by Rosselli, Ardila, Matute, and Inozemtseva (2009) in mental calculation and solving arithmetic problem tasks, these authors argued that boys presented a more efficient retrieval of arithmetic facts. von Aster (1994) hypothesised that girls seems to be more susceptible to anxiety and depression, which may affect their performance in maths exam. This assumption was supported by the study of Krinzinger and Kaufmann (2006) in that girls reported higher levels of math anxiety and/or more negative attitudes towards math than boys.

In a cross-cultural study of Brazilian, French and Swiss children, aged 7 to 10 years Brazilian children were from central and suburbs of Brasília city, recruited in public and private schools (Dellatolas et al., 2000). The authors obtained an age effect on the Score A, which is formed by the core tasks of the battery: two involving number transcription, the two tasks of number comparison, and the two tasks of calculation. French children from 7 to 8 years old obtained better scores than children from other nationalities; however, the groups showed equivalent performance at age 10 . In regards to the Brazilian sample, children from the suburbs presented lower scores than children from central areas in specific tasks: at ages 7-8 in written comparison, dictation and reading of numbers; at ages 8-9 in mental calculation and arithmetic problem; at ages 9-10 in mental calculation and contextual estimation. Boys presented better performance than girls in both oral and written comparison of numbers. However, this study had an irregular distribution of children by age range in different schooling grades, for instance a child at age 9 to 10 could study at $2^{\text {nd }}$ or $3^{\text {rd }}$ grade, and this can be a confounding factor in terms of schooling achievement. Besides, the socioeconomic status was estimated according to the city regions (central versus suburb) instead of being objectively measured, which makes the discrimination of environment and socioeconomic aspects difficult.

Other Brazilian neuropsychological studies in mathematical skills remain rare (Dias et al., 2009). Correa and Meireles (2000) observed a progressive development in the capacity to establish relationship of inverse order between divisor and quotient in children aged 5-7 years. Haydu, Costa, and Pullin (2006) demonstrated that the presentation in different forms of arithmetic problems 


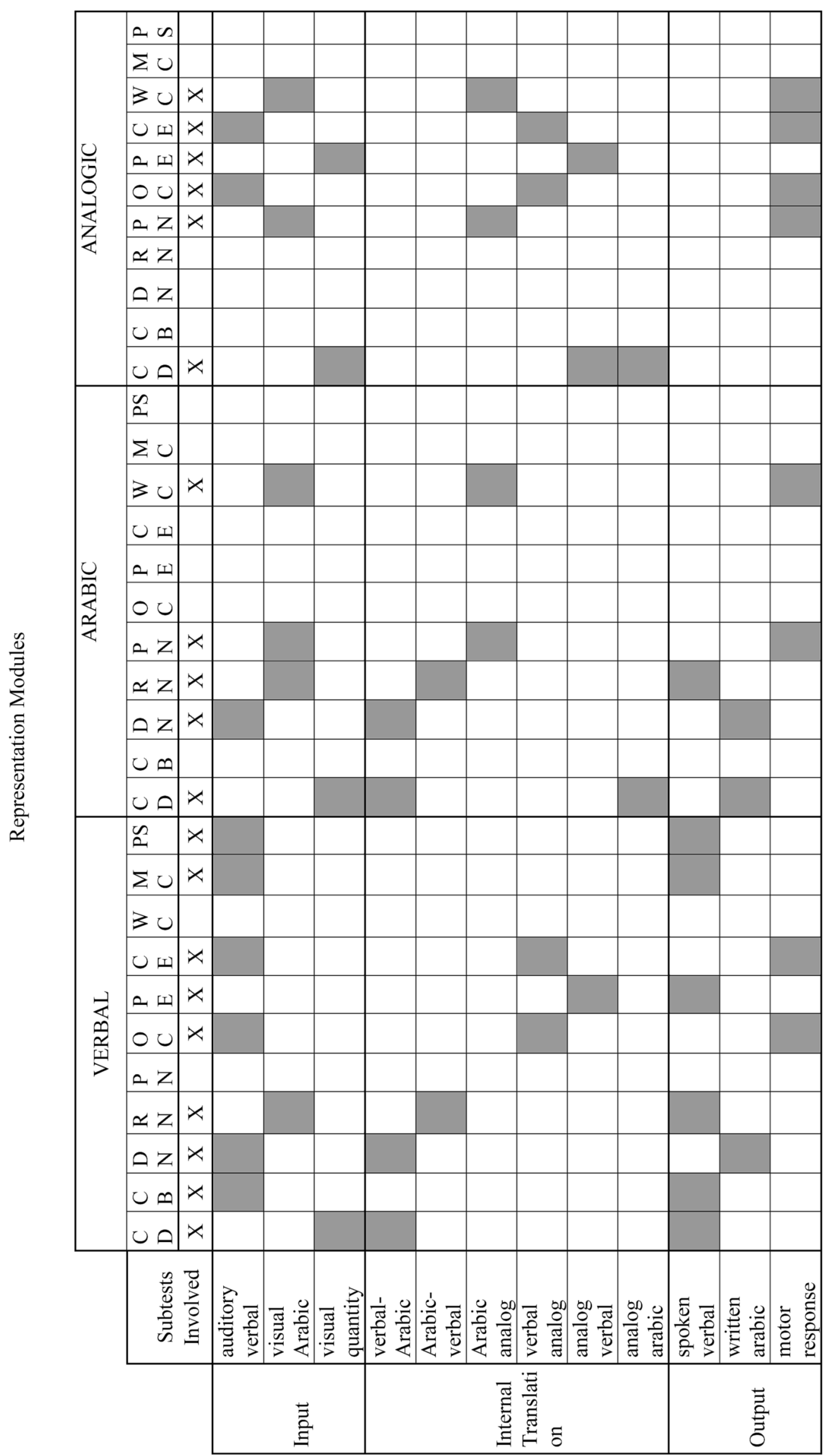

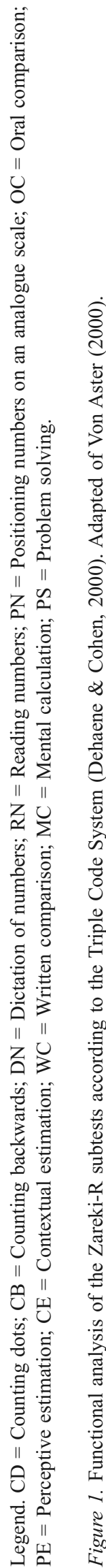


facilitates the addition operation. Raad, Pimentel, and Almeida (2008) did not find differences on arithmetic performance of boys and girls from the $2^{\text {nd }}$ grade in two public schools of Aracaju city in Sergipe State. Oliveira and Tourinho (2001) showed better performance for problems solving by the end of the $1^{\text {st }}$ grade in comparison with the beginning of it. These studies are useful contributions, however, they assessed particular aspects of mathematical skills in restrict age bands, using different instruments, and, therefore, it is difficult to generalize the results in terms of mathematical development, and the factors that interfere in its functioning.

More recently a revised version of the Neuropsychological test battery for Number Processing and Calculation in Children, recognized as Zareki-R was released (von Aster $\&$ Dellatolas, 2006). However, studies with the revised version still sparce (von Aster \& Dellatolas, 2006; Rotzer et al., 2009), and the present work is the first normative study of the Zareki-R into Portuguese language. Silva and Santos (2011) assessed Brazilian children with learning disabilities and remarkable difficulties in arithmetic using the Zareki-R. These children presented a global score one and a half standard-deviation below children with learning difficulties in reading and writing, and were impaired in both number processing (dictation of numbers) and calculation (mental calculation and arithmetic problem solving). Their impairment was even worse - two standard deviation below - when compared with typically developing children, which is compatible with the first criterion of ICD10 for Developmental Dyscalculia (Silva \& Santos, 2009). Rotzer et al. (2009) also used Zareki-R and found similar results. Moreover, Silva and Santos (2011) observed significantly positive correlations between mental calculation and problem solving subtests and visuospatial and phonological working memory tasks. Santos and Silva (2008) obtained a high positive correlation between the Zareki-R total score $(r=.73, p<.05)$ and the subtest "arithmetic" of the SAT, School Achievement Test (TDE, Teste de Desempenho Escolar; Stein, 1994), which indicates the construct validity of the Zareki-R.

The objectives of the present study were to: a) assess number processing and mental calculation in Brazilian children aged 7-12 years from public schools using the Zareki-R in order to obtain normative data for Portuguese speakers; b) identify how environment, age and gender factors influence the development of these mathematical skills; c) investigate the validity of the construct of the Zareki-R by the contrast with the Arithmetic subtest of WISC-III. The authors hypothesize that rural children might present a slight inferior performance than urban in both number processing and mental calculation, therefore, a global difference in mathematical skills. Besides, we suppose that older children will perform better than younger, and boys will perform better than girls in mental calculation.
Method

Prior to testing, informed written consent for both experiments was obtained from the children's parents. It was explained to each child that the experiment could be discontinued at any time. The Ethics Committee of UNESP, São Paulo State University approved the study, case $n^{\circ}$ 0095/2005.

\section{Participants}

Participants were 172 children (86 boys) aged 7-12 years. In regards to gender the children were distributed across age bands: twelve boys at age 7 , ten boys at age 8 , eighteen boys at age 9 , twenty-five boys at age 10 , eleven boys at age 11 and ten boys at age 12. The children were raised in urban area of Assis and Ourinhos cities in São Paulo State $(N=119)$ or in rural area from the same region $(N=53)$. The children were recruited in government schools from $1^{\text {st }}$ to $6^{\text {th }}$ grades. The schools were selected according to three aspects: a) being public schools, b) attending children at the target age bands, and c) attending also children raised in rural areas. It is important to mention that the rural children of this sample lived in the rural environment but studied in the same urban schools than their counterparts.

All of the children were Brazilian nationals, native Portuguese speakers, and non-bilingual. The age bands and schooling grades were equivalent in all cases. The inclusion criterion was normal intellectual level: 50 children of the sample were assessed by the Raven's Coloured Progressive Matrices (percentile $>24$ and < 75; Angelini, Alves, Custódio, Duarte, \& Duarte, 1999) and 122 children were assessed by the Wechsler Intelligence Scale for Children WISC III (IQ >80 and <120; Wechsler, 2002). The intellectual level was assessed in order identify potential outliers; participants were recruited for two different projects, which explain the use of Raven's matrices for some of them.

None of the children was identified as presenting learning disabilities, emotional disturbances, motor difficulties, speech or hearing impairments, or neurological or psychiatric diagnosis, based on parent and teacher reports. The socioeconomic status (SES) was assessed by the Brazilian Association of Marketing Research Institutes Scale, which stratifies in five classes from A/richest to E/poorest (ABIPEME; Almeida \& Wickerhauser, 1991). Difference in SES between the two groups was found, in that urban children $M=54.89,(S D=18.44)$ obtained higher scores $(t=5.61 ; p<.001)$ than rural children $M=38.45,(S D$ $=15.16)$, these mean scores represent the opposite extremes boundaries of middle class (38-58 points). Sociodemographic information is presented on Table 1 .

\section{Material}

The Zareki-R (von Aster \& Dellatolas, 2006) assesses the number representation in children considering cognitive abilities that are prerequisites for the acquisition of 
Table 1

Sample description by groups

\begin{tabular}{lcccccc}
\hline & \multicolumn{2}{c}{ Total } & \multicolumn{2}{c}{ Urban } & \multicolumn{2}{c}{ Rural } \\
& $N$ & $\%$ & $N$ & $\%$ & $N$ & $\%$ \\
\hline Age (years) & & & & & & \\
Age 7 & 30 & 17.44 & 23 & 19.33 & 7 & 13.21 \\
Age 8 & 20 & 11.63 & 11 & 9.24 & 9 & 16.98 \\
Age 9 & 38 & 22.09 & 29 & 24.37 & 9 & 16.98 \\
Age 10 & 44 & 25.58 & 33 & 27.73 & 11 & 20.75 \\
Age 11 & 21 & 12.21 & 13 & 10.92 & 8 & 15.09 \\
Age 12 & 19 & 11.05 & 10 & 8.40 & 9 & 16.98 \\
Gender & & & & & & \\
Boys & 86 & 50 & 60 & 50.42 & 26 & 49.06 \\
Girls & 86 & 50 & 59 & 49.58 & 27 & 50.94 \\
Total & 172 & 100 & 119 & 100 & 53 & 100 \\
\hline
\end{tabular}

Legend. $N=$ number of participants; $\%=$ percentage of cases

arithmetic skills. Zareki-R has been originally published in German and French language versions (von Aster, Weinhold Zulauf, \& Horn, 2006; von Aster \& Dellatolas, 2006; respectively) with its respective standardization. As for the French version, von Aster and Dellatolas (2006) found significant and high correlations between Zareki-R scores and the mathematic part of the Test of Scholar Achievement in different grades (TAS, Test d'Acquisitions Scolaires Francais et Mathematiques; Lepez \& Riquier, 1997) reported by children's teachers.

The Zareki-R has 11 subtests specialized in mathematical skills, nine of them assess number processing (i-ix) and two assess calculation (x-xi): i) Counting dots (CD): Children have to enumerate different set of dots. The scoring system considers the number of results. Qualitatively, it is considered: production of the usual sequence of spoken numbers, oral and manual synchronization while pointing and counting dots, visual control for discrimination of the dots already counted and remaining items, transcoding the information from spoken verbal number to Arabic digit form (the number of items, i.e., the k-value is 6) ; ii) Counting backwards $(C B)$ : the children must count the dots in backward the sequences: from 23 to 1 and from 67 to 54 (Items k =2); iii) Dictation of numbers $(D N)$ : the child is asked to write, in Arabic numerals, eight numbers presented orally (e.g. 14), (Items $\mathrm{k}=8$ ); iv) Reading numbers $(R N)$ : the child is asked to read loudly eight numbers written in Arabic numerals, such as 15 and 6485, (Items k $=8$ ); v) Positioning numbers on an analogue scale (PN): the scales are vertical lines represented with a "0" at the bottom and a "100" at the top, which are transacted by 4 small horizontal lines at different locations. The child is asked to point to the horizontal which corresponds to an Arabic numeral, aurally or visually presented by the examiner (Items k =12); vi) Oral comparison (OC): Eight pairs of numbers are presented aurally (e.g., 34601 and 9678) and the child must judge which one is larger (Items $\mathrm{k}=8$ ); vii) Perceptive estimation (PE): The child has to give orally an estimative, without counting, in of the quantities of items shown in a picture, visually presented by 5 seconds, for example the number of balls in the picture (the precise answer is 57 balls), (Items $\mathrm{k}=8$ ); viii) Contextual estimation (CE): The child must judge sentences in terms of coherence between quantities and context, for instance: "ten leaves on a tree" is 'little', 'median' or a 'lot'?, (Items k=10); ix) Written comparison (WC): Pairs of numbers in Arabic numeral form are presented visually, for instance, 1007 and 1070 , and the child must judge which one is larger, (Items $\mathrm{k}=10$ ); $\mathrm{x}$ ) Mental calculation (MC): Eight additions, eight subtractions, and six multiplications are presented aurally (e.g.: $5+8 ; 14-6$, and 3 x 2), (Items k = 22); xi) Problem solving (PS): The child has to solve six numerical problems of increasing complexity. The first story problem is: 'Peter has 12 marbles; He gave 5 to his friend Anne; how many marbles Peter has now?', (Items $\mathrm{k}=6$ ). The battery also includes a subtest to measure phonological working memory, however, it is not included in the total score: xii) Memory of Digits (MD): This requires the forward (FDS) and backward (BDS) repetition of digit sequences of increasing length, three sequences of each length were performed. In the FDS the child repeats the digits in the same order as the experimenter spoke them, (Items $\mathrm{k}=24$ ). In the BDS, the subject repeats the digits in reverse order. Additionally, as presented by Dellatolas et al. (2000), the Score A is

Table 2

Sociodemographic aspects by groups

\begin{tabular}{lccccccccc}
\hline & \multicolumn{2}{c}{ Total } & \multicolumn{2}{c}{ Urban } & \multicolumn{2}{c}{ Rural } \\
& $N$ & $M(S D)$ & & & $N$ & $M(S D)$ & & $N$ & $M(S D)$ \\
\hline SES & 160 & 49.45 & $(19.03)$ & & 107 & 54.89 & $(18.44)$ & 53 & $38.45 \quad(15.16) *$ \\
WISC-III- IQV & 122 & 106.56 & $(11.75)$ & 69 & 109.65 & $(10.89)$ & 53 & $102.46(11.68) *$ \\
CPM\# & 50 & 66.50 & $(20.01)$ & 50 & & & & - \\
\hline
\end{tabular}

$\left(^{*}\right) p<.05 ;\left(^{\#}\right)$ urban children from Ourinhos city aged 9 to 10 years. Legend. $N=$ number of participants; $M=$ mean; $S D=$ standard deviation; SES = socioeconomic status; WISC-III = Wechsler Intelligence Scale for Children; IQV = Verbal Intelligence Quotient; $\mathrm{CPM}=$ Raven's Coloured Progressive Matrices. 
calculated by the sum of the six following subtests of ZAREKI-R: dictation of number, reading numbers, mental calculation, problem solving, oral comparison and written comparison.

\section{Procedures}

The children were assessed with a larger battery of neuropsychological tests, involving short and long termmemory for visuospatial and verbal stimuli, which will not be reported in this article. The neuropsychological assessment was carried out individually at child's school in a quiet room. The Zareki-R was administered in a single session and engaged 30-minute in average; the subtests order was not fixed, but verbal tasks (MD, DN, CB, MC, OC, CE, and $\mathrm{PS}$ ) were alternated with visuomotor e perceptive ones (CD, RN, WR, PE, and PN).

\section{Statistical analyses}

The analyses were carried out with STATISTICA, version 5.0 (Statsoft, 1995). Three sets of analyses were performed. In the first, multivariate analysis of variance (MANOVA) were carried out for Zareki-R subtests. In this case, the between-subject factors were 2 groups (urban and rural), while the within-subjects factors were the scores in each subtest of Zareki-R, except the subtest Memory of Digits. The t-test was carried out for the Total score, Score A, and Memory of Digits of Zareki-R, with the same betweensubject factors. Due to differences between groups on Zareki$\mathrm{R}$ subtests, the subsequent analyses were conducted with group as covariant.

In the second set of analyses, multivariate analysis of covariance (MANCOVA) - group as a covariant - were carried out, between-subject factors were 6 ages (from 7 to 12 years) and 2 genders (male and female) and the same within-subject factors were used to investigate the factors that determine the main effects obtained. Analyses of covariance (ANCOVA) - group as a covariant - were performed for the Total score, Score A, and Memory of Digits of Zareki-R, with the same within- and betweensubject factors. In the first and second sets of analyses the Scheffé post hoc test was used with a significant alpha level of $p \leq .05$.

In the third set, Pearson's product moment correlations between scores in Zareki-R and Arithmetic of WISC-III, and Memory of Digits of Zareki-R were carried out. For the discussion, we adopted moderate to high correlations $(r>.40)$ as minimum score. To assess the effect size of group and gender effect was used Cohen's d calculated

Table 3

ZAREKI-R performance in Brazilian children by groups and gender

\begin{tabular}{|c|c|c|c|c|c|c|c|c|c|c|c|c|}
\hline & \multicolumn{2}{|c|}{ Urban $(N=119)$} & \multicolumn{2}{|c|}{ Rural $(N=53)$} & \multirow{2}{*}{$p$} & \multirow{2}{*}{ Cohen $d$} & \multicolumn{2}{|c|}{ Boys $(\mathrm{N}=86)$} & \multicolumn{2}{|c|}{ Girls $(\mathrm{N}=86)$} & \multirow{2}{*}{$p$} & \multirow{2}{*}{ Cohen $d$} \\
\hline & $M$ & $(S D)$ & $M$ & $(S D)$ & & & $M$ & $(S D)$ & $M$ & $(S D)$ & & \\
\hline $\mathrm{CD}$ & 3.49 & $(.82)$ & 3.58 & $(.72)$ & .45 & -.11 & 3.53 & $(.79)$ & 3.50 & $(.79)$ & .77 & .03 \\
\hline $\mathrm{CB}$ & 3.26 & $(1.09)$ & 2.96 & $(1.18)$ & .10 & .26 & 3.31 & $(.99)$ & 3.02 & $(1.24)$ & .08 & .25 \\
\hline $\mathrm{DN}$ & 13.26 & $(4.11)$ & 12.42 & $(4.27)$ & .21 & .20 & 13.42 & $(3.85)$ & 12.58 & $(4.44)$ & .18 & .20 \\
\hline $\mathrm{RN}$ & 14.16 & $(3.79)$ & 13.83 & (3.93) & .60 & .08 & 14.48 & $(3.57)$ & 13.64 & $(4.03)$ & .15 & .22 \\
\hline $\mathrm{PN}$ & 16.46 & $(5.07)$ & 14.99 & $(5.31)$ & .08 & .28 & 16.68 & $(5.13)$ & 15.33 & $(5.17)$ & .08 & .26 \\
\hline $\mathrm{OC}$ & 14.08 & $(2.57)$ & 13.25 & $(3.32)$ & .07 & .27 & 14.48 & $(2.17)$ & 13.16 & $(3.26)$ & $<.01^{*}$ & .47 \\
\hline $\mathrm{PE}$ & 6.08 & $(2.22)$ & 6.40 & $(2.37)$ & .40 & -.13 & 6.38 & $(2.26)$ & 5.98 & $(2.26)$ & .24 & .17 \\
\hline $\mathrm{CE}$ & 12.72 & $(4.67)$ & 14.04 & $(4.89)$ & .09 & -.27 & 12.84 & $(5.01)$ & 13.42 & $(4.52)$ & .42 & -.12 \\
\hline WC & 18.97 & $(2.06)$ & 18.23 & $(2.62)$ & $.04 *$ & .31 & 19 & (1.98) & 18.49 & $(2.51)$ & .13 & .22 \\
\hline $\mathrm{MC}$ & 29.88 & (11.28) & 26.51 & (11.54) & .07 & .29 & 30.48 & (11.37) & 27.21 & (11.33) & $.05^{*}$ & .28 \\
\hline PS & 7.33 & (3.64) & 6.58 & $(3.62)$ & .21 & .20 & 7.99 & $(3.59)$ & 6.21 & $(3.48)$ & $<.01 *$ & .50 \\
\hline Total & 139.56 & $(31.85)$ & 132.76 & $(33.56)$ & .20 & .20 & 142.58 & $(30.97)$ & 132.35 & $(33.25)$ & $.03 *$ & .31 \\
\hline Score A & 97.68 & $(24.02)$ & 90.79 & $(25.01)$ & .08 & .28 & 99.82 & (23.36) & 91.29 & (24.94) & $<.01 *$ & .35 \\
\hline MD & 25.05 & $(6.83)$ & 20.22 & (5.19) & $<.01$ & .79 & 23.53 & $(6.93)$ & 23.60 & $(6.59)$ & .89 & -.01 \\
\hline
\end{tabular}

$\left(^{*}\right) p \leq .05$. Gender effect by ANCOVA, group as covariant. Legend. Zareki-R = Neuropsychological Tests Battery of for Number Processing and Mental Calculation in children, Revised; $N=$ number of participants; $M=$ mean; $S D=$ standard deviation; $\mathrm{CD}=\mathrm{Counting}$ dots; $\mathrm{CB}=$ Counting backwards; $\mathrm{DN}=$ Dictation of numbers; RN = Reading numbers; PN = Positioning numbers on an analogue scale; $\mathrm{OC}=$ Oral comparison; $\mathrm{PE}=$ Perceptive estimation; $\mathrm{CE}=$ Contextual estimation; $\mathrm{WC}=$ Written comparison; $\mathrm{MC}=\mathrm{Mental}$ calculation; $\mathrm{PS}=$ Problem solving. Score $\mathrm{A}=$ is calculated by the sum of the six following subtests of Zareki-R: dictation of number, reading numbers, mental calculation, problem solving, oral comparison and written comparison. $\mathrm{MD}=$ Memory of Digits. 
Table 4

ZAREKI-R performance in Brazilian children by age

\begin{tabular}{|c|c|c|c|c|c|c|c|c|c|c|c|c|}
\hline & \multicolumn{2}{|c|}{ Age $7(N=30)$} & \multicolumn{2}{|c|}{ Age $8(N=20)$} & \multicolumn{2}{|c|}{ Age $9(N=38)$} & \multicolumn{2}{|c|}{ Age $10(N=44)$} & \multicolumn{2}{|c|}{ Age $11(N=21)$} & \multicolumn{2}{|c|}{ Age $12(N=19)$} \\
\hline & $M$ & $(S D)$ & $M$ & $(S D)$ & $M$ & $(S D)$ & $M$ & $(S D)$ & $M$ & $(S D)$ & $M$ & $(S D)$ \\
\hline $\mathrm{CD}$ & 3.40 & $(.89)$ & 3.50 & $(.83)$ & 3.26 & $(.89)$ & 3.68 & (.64) & 3.67 & $(.66)$ & 3.68 & $(.75)$ \\
\hline $\mathrm{CB}^{\mathrm{a}}$ & 1.97 & $(1.43)$ & 3.25 & $(1.21)$ & 3.21 & $(.99)$ & 3.55 & $(.76)$ & 3.57 & $(.60)$ & 3.58 & $(.51)$ \\
\hline $\mathrm{DN}^{\mathrm{b}}$ & 6.07 & $(3.81)$ & 11.65 & $(3.76)$ & 14.45 & $(2.42)$ & 15.23 & $(1.18)$ & 15.05 & $(1.36)$ & 15.05 & $(1.03)$ \\
\hline $\mathrm{RN}^{\mathrm{b}}$ & 7.67 & $(4.61)$ & 13.30 & $(3.33)$ & 15.53 & $(1.25)$ & 15.80 & (.67) & 16.00 & $(.00)$ & 15.84 & $(.37)$ \\
\hline $\mathrm{PN}^{\mathrm{a}}$ & 10.38 & $(5.96)$ & 15.53 & $(5.33)$ & 15.61 & $(4.46)$ & 18.41 & $(2.97)$ & 17.86 & $(4.01)$ & 18.58 & $(3.01)$ \\
\hline $\mathrm{OC}^{\mathrm{d}}$ & 10.67 & $(3.49)$ & 12.15 & $(3.80)$ & 15.00 & $(1.41)$ & 14.52 & (1.64) & 15.00 & $(1.30)$ & 15.26 & $(1.37)$ \\
\hline PE & 5.20 & $(2.20)$ & 5.40 & $(2.44)$ & 6.42 & $(2.42)$ & 6.73 & $(2.12)$ & 6.33 & (1.98) & 6.63 & $(2.03)$ \\
\hline $\mathrm{CE}^{\mathrm{a}}$ & 9.13 & $(3.81)$ & 13.40 & $(4.45)$ & 12.68 & $(4.73)$ & 14.14 & $(4.89)$ & 14.48 & $(4.29)$ & 16.21 & $(2.49)$ \\
\hline $\mathrm{WC}^{\mathrm{a}}$ & 16.33 & $(3.07)$ & 18.40 & $(2.87)$ & 19.26 & (1.08) & 19.41 & $(1.70)$ & 19.52 & $(0.87)$ & 19.47 & $(1.47)$ \\
\hline $\mathrm{MC}^{\mathrm{c}}$ & 12.47 & $(9.37)$ & 25.15 & $(11.82)$ & 31.26 & $(8.00)$ & 34.80 & $(6.72)$ & 34.43 & $(6.93)$ & 33.79 & (6.09) \\
\hline $\mathrm{PS}^{\mathrm{c}}$ & 2.77 & $(3.33)$ & 5.50 & $(3.86)$ & 7.53 & (3.13) & 8.66 & $(2.51)$ & 8.62 & (2.01) & 9.47 & $(1.81)$ \\
\hline Total $^{c}$ & 85.51 & $(27.46)$ & 127.17 & $(31.70)$ & 144.21 & (18.38) & 154.91 & $(14.25)$ & 154.52 & $(12.85)$ & 157.58 & (11.81) \\
\hline Score $A^{b}$ & 55.96 & $(21.26)$ & 86.10 & $(24.12)$ & 103.02 & (11.95) & 108.40 & (10.58) & 108.61 & $(8.72)$ & 108.89 & $(8.96)$ \\
\hline MD & 21.46 & (6.14) & 23.90 & (8.39) & 23.00 & $(6.25)$ & 24.63 & $(6.96)$ & 22.95 & $(7.00)$ & 25.89 & $(5.39)$ \\
\hline
\end{tabular}

Legend. Age effect by MANCOVA, group as covariant; Scheffé post-hoc: (a) $7<8$-12; (b) $7<8<9-12$; (c) $7<8$ and $8<10-12$; (d) $7-8<9-12 ; p \leq .05$ in all cases. Zareki-R = Neuropsychological Tests Battery of for Number Processing and Mental Calculation in children, Revised; $N=$ number of participants; $M=$ mean; $S D=$ standard deviation; $\mathrm{CD}=$ Counting dots; $\mathrm{CB}=\mathrm{Counting}$ backwards; $\mathrm{DN}$ $=$ Dictation of numbers; $\mathrm{RN}=$ Reading numbers; $\mathrm{PN}=$ Positioning numbers on an analogue scale; OC $=$ Oral comparison; $\mathrm{PE}=$ Perceptive estimation; $\mathrm{CE}=$ Contextual estimation; $\mathrm{WC}=$ Written comparison; $\mathrm{MC}=$ Mental calculation; $\mathrm{PS}=\mathrm{Problem}$ solving; $\mathrm{MD}=$ Memory of Digits. Score A= is calculated by the sum of the six following subtests of Zareki-R: dictation of number, reading numbers, mental calculation, problem solving, oral comparison and written comparison.

through the free software (Devilly, 2005); small, median, and large effects are respectively correspondent to effect sizes of .20, .50, and .80 (Rice \& Harris, 2005).

Finally, considering that working memory could be a possible factor explaining the results, using the same withinand between-factors of first and second sets we carried out exploratory analyses with Memory of Digits as covariant, and the results were similar to the analyses reported below in that group was the covariant.

\section{Results}

Tables 3 and 4 present the results obtained with the Zareki-R by groups, gender and age, respectively. In general, urban children had higher scores than rural in the subtest Written comparison and Memory of Digits, the performance increased with age, and boys had higher scores than girls in Mental calculation, Oral comparison, Problem solving, and Total score.

Group effect. A 2 (group) x 11 (subtest) MANOVA was performed. A group effect was observed $[R(11,160)$ $=2.11 ; p=.02]$. Urban children were better than rural in Written comparison $(p=.04)$. No effect of group was observed by ANOVA in the Total Score $(t=1.27 ; p=.63)$ and Score A of Zareki-R $(t=1.71 ; p=.70)$. There was group effect in the subtest Memory of Digits of Zareki-R $(t=4.58 ; p=.02)$, in that urban children performed better than rural.

Gender effect. A 2 (gender) x 11 (subtest) MANCOVA was performed, group as a covariant, and revealed a gender effect $[R(11,159)=2.43 ; p<.01]$. Boys performed better than girls in Mental calculation $(p=.05)$, Oral comparison $(p<.01)$, and Problem solving $(p=.11)$. ANCOVAs group as a covariant - indicated gender effect to the Total score $[F(1,169)=4.30 ; p=.03]$ and Score A $[F(1,169)$ $=5.32 ; p<.02]$; boys performed better than girls, but not to Memory of Digits $[F(1,169)=.01 ; p=.89]$.

Age effect. A 6 (age) x 11 (subtest) MANCOVA was performed, group as a covariant, and revealed an age effect $[R(55,721)=5.47 ; p<.001]$. ANCOVA - group as a covariant - observed an age effect to the Total Score $[F(5$, $165)=58.57 ; p<.001]$, and Score A $[F(5,165)=63.94$; $p<.001]$. ANCOVA - group as a covariant - also observed an age effect to Memory of Digits $[F(5,165)=2.33 ; p=$ .04], but the post-hoc test did not discriminated the differences. Except for Counting dots and Perceptive estimation subtests, the age effect was observed in all tasks. 7-year-old children performed worse than all other ages for the other subtests and Score A, except for Oral comparison, in that 7- and 8-year-old children performed worse than 9to 12-year-old children. 8-year-old children performed worse 
than 9- to 12-year-old children in Dictation of numbers, Reading numbers, and Score A, and worse than 10- to 12year-old children in Mental calculation, Problem solving and Total score.

Exploratory analysis with gender and age as covariants altogether in MANCOVA and ANCOVAs for the total score, Memory of Digits, Zareki-R subtests, and for Score A indicated that there were no interactions between these factors.

\section{Correlation between Zareki- $R$ and Arithmetic of WISC-III or Memory of Digits}

The correlation matrix was calculated considering the four-step developmental model of number acquisition (von Aster \& Shalev, 2007) which states that number line development is associated with working memory (subtest memory of dots). Moreover, the subtest Arithmetic of WISCIII was used as a gold standard for the assessment of mathematical skills. The results revealed significant and positive relationship between all the subtests of Zareki-R and the subtest Arithmetic of WISC-III. Moderate correlations were observed to the following subtests: Counting backwards $(r=.49)$, Dictation of numbers $(r=$ .49), Mental calculation $(r=.49)$, Reading numbers $(r=$ $.49)$, Oral comparison $(r=.41)$, Problem solving $(r=.58)$, Total score $(r=.65)$, and Score A $(r=.62)$. There were significant and positive correlation between the Memory of Digits and the others subtest of Zareki-R, except for Counting Dots $(p=.10)$ and Perceptive estimation $(p=.87)$, but none of them were over .4. See Table 5.
Discussion

The present study investigated the mathematical skills such as calculation and number processing of Brazilian children aged 7 to 12 years from public schools in two cities of São Paulo State and identified some factors that influenced the development of these abilities. The performance was mainly age and gender-related, and indicated minimal environmental influence.

As for the environmental factor, rural children achieved lower score than urban children only in two tasks (Written comparison and Memory of Digits), with preserved calculation; whereas in the study of Koumoula et al. (2004) rural children obtained lowers scores in seven subtests of ZAREKI (von Aster, 2001), including Written comparison, but not Memory of Digits. In previous studies it was suggested that a low socioeconomic level and educational environment could determine such differences (Dellatolas et al., 2000; Koumoula et al., 2004). In the present study, socioeconomic status was objectively assessed, rather than inferred by the environment factor, and the statistical analysis indicated that rural children in fact had low socioeconomic scores than urban children. In spite of it, the rural group showed a slight low score restricted to one aspect of number processing; and, even though, the effect size showed that this difference had small magnitude. It means that, despite of this socioeconomic discrepancy both groups performed Zareki-R almost similarly. Since all rural children studied in the same schools as the urban children, therefore obtain the same educational stimulation, we consider that the pedagogy method is a more specific

Table 5

Correlation between Zareki-R and Arithmetic of WISC-III

\begin{tabular}{lcc}
\hline & $\begin{array}{c}\text { Arithmetic of WISC-III } \\
(N=122)\end{array}$ & $\begin{array}{c}\text { MD of Zareki-R } \\
(N=172)\end{array}$ \\
\hline Counting dots & .18 & .12 \\
Counting backwards & $.49^{*}$ & .35 \\
Dictation of numbers & $.49^{*}$ & .35 \\
Reading numbers & $.49^{*}$ & .27 \\
Positioning numbers on an analogue scale & .33 & .33 \\
Oral comparison & $.41^{*}$ & .21 \\
Perceptive estimation & .22 & -.01 \\
Contextual estimation & .36 & .25 \\
Written comparison & .38 & .32 \\
Mental calculation & $.62^{*}$ & .36 \\
Problem solving & $.58^{*}$ & .38 \\
Total score & $.64^{*}$ & .39 \\
Score A & $.62^{*}$ & .38 \\
\hline
\end{tabular}

$\left(^{*}\right)$ Moderate and high correlations $r>.40 ; p<.05$. Legend. Zareki-R = Neuropsychological test battery for Number Processing and Calculation in Children, Revised; WISC-III = Wechsler Intelligence Scale for Children; MD= Memory of Digits; Zareki-R = Neuropsychological Tests Battery of for Number Processing and Mental Calculation in children, Revised. 
determinant of the arithmetic performance than the socioeconomic status.

The performance was age-related, even controlling statistically the environmental factor, in that children aged 7 and 8 years obtained lower scores in Zareki-R in comparison to older children, except in two subtests: counting dots and perceptive estimation. This result was expected since counting dots is an ability related to the core verbal system of the four-step Developmental Model of Numerical Cognition, which develops at the preschool age (von Aster \& Shalev, 2007), which is consistent with Gelman and Gallistel (1978) principles, that the counting competence allows children to compare quantities and solve arithmetic using counting strategies as reasoning tools. Besides, older children have more facility to perform the battery, at least for items influenced by schooling; for example, there was ceiling effect in Reading numbers subtest at age 11 .

Dellatolas et al. (2000), Koumoula et al. (2004), and von Aster and Shalev (2007) showed that many domains of number processing and calculation are dependent on schooling achievement (Score A) and have an improvement age-related since the symbolic number representation system (verbal and Arabic) and the ordinal magnitude system (mental number line) are learnt during primary school. Therefore, mathematic skills seem to be dependent of both brain maturation (von Aster, 2000) and schooling (von Aster \& Shalev, 2007).

Boys performed better than girls at Zareki-R total score, in calculation (Mental calculation and Problem solving), and in one subtest of number processing (Oral comparison), in all cases the effect was confirmed controlling the environmental factor by the ANCOVA. However, the effect size showed that the gender difference had small magnitude for Mental calculation and Oral comparison and median magnitude for the Problem solving subtest. We consider that the differences were number representation-related rather than associated with general cognitive ability because all children had average scores on intelligence measure, phonological short-term span or other neuropsychological tests. Previous studies have found lowers scores for girls in calculation (Hein et al., 2000; Rosselli et al., 2009; von Aster, 2000) and in number comparison (Dellatolas et al., 2000; von Aster, 2000). Rosselli et al. (2009) attributed the gender effect to more efficient arithmetical fact retrieval for the boys. In our study boys and girls performed similarly all memory tasks; so, it is unlikely that long-term memory (results not reported in the present study) could explain the gender contrast. Although, we did not assessed mood or stress in our sample, Krinzinger and Kaufmann (2006) considered that the low performance of girls in arithmetic could be explained by a higher level of math anxiety and to negative attitudes toward math, what is consistent with von Aster (1994) that associated these lower scores of girls with emotional aspects.
In the present study urban children performed the subtest Memory of Digits of Zareki-R better than rural children. Many studies showed that digit span task is free from culture aspects, such as environment and socioeconomic status (Engel et al., 2009; Koumoula et al., 2004; Santos \& Bueno, 2003; Santos et al., 2005). A possible explanation for this incongruence is the scoring system of Zareki-R, in that higher score in Memory of Digits cannot be interpreted necessarily as higher span on phonological working memory, instead higher scores are associated with the consistence of correct response, because the child may have a span, for instance of four items, but failure to reproduce the three trials and consequently obtain less points than a child with the same span but that answered correctly all three trials. Moreover, the Memory of Digits presents a composite score with the sum of forward and backward trials. So, these particularities may be an artefact. In the other hand, the correlations between Memory of Digits and Zareki-R's subtests were low statistically significant (.1 to .3) and corroborate with previous studies associating arithmetic skills and working memory (Gathercole \& Alloway, 2004; Gathercole, Alloway, Willis, \& Adams, 2006; Geary, 2000; Koumoula et al., 2004; Siegel \& Ryan, 1989; Silva \& Santos, 2011; Swanson, 2006), which is also consistent with the four-step Developmental Model of Numerical Cognition (von Aster \& Shalev, 2007).

In addition, it was found moderate to high positive correlations $(r>.40)$ between Zareki-R and the subtest Arithmetic of the WISC-III, which demonstrated the Zareki$\mathrm{R}$ construct validity; however, in the Arithmetic WISC-III subtest, different components of numerical cognition are in concert, thus, it is a good measure for screening but not accurate for diagnosis. Santos and Silva (2008) showed that children who presented inferior scores in the Arithmetic subtest of the School Achievement Test (SAT; Stein, 1994), which assess only calculation according to the schooling grade expectation, were impaired in both aspects of mathematical skills - calculation and number processing when assessed by the Zareki-R. Therefore, the Zareki-R seems to be more comprehensive to assess mathematical skills than SAT and WISC-III, and seems to be an important instrument for the diagnosis of Developmental Dyscalculia.

The limitation of the present study is that the sample included children from two cities of the Sao Paulo State (Assis and Ourinhos), which restrict in part the generalization of the results, however, the results were not completely discrepant of the previous normative studies with ZAREKI and Zareki-R in general aspects (Dellatolas et al., 2000; Hein et al., 2000; Koumoula et al., 2004; von Aster, 2000; Rotzer et al., 2009). A present goal from the authors is to investigate if the current profile is equivalent in different regions of the country and include children at age 6 because recently Brazilian law anticipated the beginning of the $1^{\text {st }}$ grade of the primary school officially from age 7 to age 6 ; whereas for younger children, in 
preschool level, seems to be more suitable to assess mathematical skills by the Zareki-K (Weinhold-Zulauf, Schweiter, \& von Aster, 2003), Kindergarten adapted version in Portuguese by Santos, Paschoalini, and Molina (2006).

In conclusion, the performance of the Brazilian children at Zareki-R was slightly related to environmental, and mainly influenced by age, and gender factors. In disagreement with our previous hypothesis, rural children presented lower performance only in one number processing aspect. It is important to hallmark that the socioeconomic factor did not seems to be main determinant of this difference, since the pedagogy method produced similar performance between rural and urban children. On the other hand, as it was expected, children from 7 to 8 years old showed a global inferior scores in comparison to older children; besides, boys performed better than girls in calculation and in one aspect of number processing. These results are important to the development of the cognitive rehabilitation strategies.

\section{References}

Almeida, P. M., \& Wickerhauser, H. (1991). O critério ABA/ABIPEME - Em busca de uma atualização [The criterion ABA / ABIPEME - In search of an update]. São Paulo, Brazil: Associação Brasileira de Anunciantes/Associação Brasileira dos Institutos de Pesquisas de Mercado.

American Psychiatric Association. (2002) Diagnostic and statistical manual of mental disordes (4 ${ }^{\text {th }}$ Ed.). Washington, DC: Author.

Angelini, A. L., Alves, I. C. B., Custódio, E. M., Duarte, W. F., \& Duarte, J. L. M. (1999). Manual: Matrizes progressivas coloridas de Raven [Manual: Raven's colored progressive matrices]. São Paulo, Brazil: Centro Editor de Testes e Pesquisas em Psicologia.

Campbell, J. I. D., \& Clark, J. M. (1992). Cognitive number processing: An encoding-complex perspective. In J. I. D. Campbell (Ed.), The nature and origins of mathematical skills (pp. 457-492). Amsterdam, The Netherlands: Elsevier.

Cantlon, J. F., Platt, M. L., \& Brannon, E. M. (2009). Beyond the number domain. Trends in Cognitive Sciences, 13, 83-91. http://dx.doi.org/10.1016/j.tics.2008.11.007

Correa, J., \& Meireles, E. S., (2000). A compreensão intuitiva da criança acerca da divisão partitiva de quantidades contínuas [Children's intuitive understanding of partitive division tasks using continuous quantities]. Estudos de Psicologia, 5, 1131. http://dx.doi.org/10.1590/S1413-294X2000000100002

Dehaene, S. (1997). The number sense. Oxford, England: Oxford University Press.

Dehaene, S. (2001). Précis of the number sense. Mind and Language, 16, 16-36. http://dx.doi.org/10.1111/1468-0017.00154

Dehaene, S., \& Cohen, L. (2000). Un modèle arithmétique e fonctionnel de l'arithmétique mental [An arithmetic and functional model of mental arithmetic]. In M. Pesenti \& X. Seron (Eds.), Neuropsychologie des troubles du cálculo e du traitement dês números (pp. 191-232). Marseille, France: Solal.
Dellatolas, G., von Aster, M., Willardino-Braga, L., Meier, M., \& Deloche, G. (2000) Number processing and mental calculation in school children aged 7 to 10 years: Transcultural comparison. European Child \& Adolescent Psychiatry, 9, 102110. http://dx.doi.org/10.1007/s007870070003

Dellatolas, G., Deloche, G., Basso, A., \& Claros-Salinas, D (2001). Assessment of calculation and number processing using the EC301 battery: Cross-cultural normative data and application to left- and right-brain damaged patients. Journal of the International Neuropsychological Society, 7, 840-859.

Deloche, G. (1995). Batterie standardisée d'evaluation du calcul et du traitement des nombres [Standardized battery of assessment of calculation and number processing]. Salvador, Brazil: Editora Sarahletras.

Deloche, G., von Aster, M., Dellatolas, G., Gaillard, F., Tieche, C., \& Azema, D. (1995). Traitement des nombres et calcul en CE1 et CE2 [Number processing and calculation in Grades 1 and 2]. Approche Neuropsychologique des Apprentissages chez l'Enfant (A.N.A.E.), Hors Série, 42-51.

Deloche, G., Dellatolas, G., Vendrell, J., \& Bergego, C. (1996). Calculation and number processing: Neuropsychological assessment and daily activities. Journal of the International Neuropsychological Society, 2, 177-180. http://dx.doi.org/ $10.1017 / \mathrm{S} 1355617700001028$

Deloche, G., Souza, L., Willadino-Braga, L., \& Dellatolas, G. (1999). A calculation and number processing battery for clinical application in illiterates and semi-literates. Cortex, 35, 503521. http://dx.doi.org/10.1016/S0010-9452(08)70815-3

Deloche, G., \& Wilmes, K. (2000). Cognitive neuropsychological models of adult calculation and number processing: the role of the surface format numbers. European Child and Adolescent Psychiatry, 9, 27-40. http://dx.doi.org/10.1007/s007870070007

Devilly, G. J. (2005). The effect size generator for Windows (Version 4.0) [computer programme]. Brain Sciences Institute, Swinburne University, Australia.

Dias, N. M., Trevisan, B. T., Menezes, A., Tortella, G., Hipólito R., Montiel, J. M., ... Seabra, A. G. (2009). Habilidade aritmética: Influências da memória de trabalho e raciocínio não verbal [Arithmetic skills: Influences of working memory and nonverbal reasoning.]. In J. M. Montiel \& F. C., Capovilla (Org.), Atualização em transtornos de aprendizagem [Updates on learning disorders]. (pp. 325-340). São Paulo, Brazil: Artes Médicas.

Engel, P., Santos, F. H., \& Gathercole, S. E. (2008). Are working memory measures free of socio-economic influence? Journal of Speech, Language, and Hearing Research, 51, 1580-1587. http://dx.doi.org/10.1044/1092-4388(2008/07-0210)

Gathercole, S. E., \& Alloway, T. P. (2004). Working memory and classroom learning. Professional Association for Teachers of Students with Specific Learning Difficulties, 17, 2-12.

Gathercole, S. E., Alloway, T. P., Willis, C., \& Adams, A. (2006). Working memory in children with reading disabilities. Journal of Experimental Child Psychology, 93, 265-281. http://dx.doi. org/10.1016/j.jecp.2005.08.003

Geary, D. C., Frensch, P. A., \& Wiley, J. G. (1993). Simple and complex mental subtraction: Strategy choice and speed-of- 
processing differences in younger and older adults. Psychology and Aging, 8, 242-256. http://dx.doi.org/10.1037/08827974.8.2.242

Geary, D. C. (1995). Reflections of evolution and culture in children's cognition: Implications for mathematical development and instruction. American Psychologist, 50, 24-37. http://dx.doi.org/10.1037/0003-066X.50.1.24

Geary, D. C. (2000). From infancy to adulthood: The development of arithmetical abilities. European Child and Adolescent Psychiatry, 9, 11-16. http://dx.doi.org/10.1007/s007870070004

Gelman R., \& Gallistel C. R. (1978). The child's understanding of number. Cambridge, MA: Harvard University Press.

Gross-Tsur, V., Manor, O., \& Shalev, R. S. (1996). Developmental dyscalculia: Prevalence and demographic features. Developmental Medicine and Child Neurology, 38, 25-33. http://dx.doi.org/10.1111/j.1469-8749.1996.tb15029.x

Haydu, V. B., Costa, L. P., \& Pullin, E. M. M. P. (2006). Resolução de problemas aritméticos: Efeito de relações de equivalência entre três diferentes formas de apresentação dos problemas [Arithmetic problem-solving: Effect of equivalence relations between three different forms of presenting problems]. Psicologia Reflexão e Crítica, 19, 44-52. http://dx.doi.org/ 10.1590/S0102-79722006000100007

Hein J., Bzufka M. W., \& Neumärker K. J. (2000). The specific disorder of arithmetic skills. Prevalence studies in a rural and an urban population sample and their clinico-neuropsychological validation. European Child \& Adolescent Psychiatry, 9, 87-101. http://dx.doi.org/10.1007/s007870070012

Iuculano, T., Tang, J., Hall, C. W. B., \& Butterworth, B. (2008). Core information processing deficits in developmental dyscalculia and low numeracy. Developmental Science, 11, 669-680. http://dx.doi.org/10.1111/j.1467-7687.2008.00716.x

Koumoula, A., Tsironi, V., Stamouli, V., Bardani, I., Siapati, S., Graham, A., ... von Aster, M. (2004). An epidemiological study of number processing and mental calculation in Greek schoolchildren. Journal of Learning Disabilities, 37, 377-388. http://dx.doi.org/10.1177/00222194040370050201

Krinzinger, H., \& Kaufmann, L. (2006). Rechenangst und rechenleistung [Math anxiety and arithmetic skills]. Sprache Stimme Gehor, 30, 160-164.

Lepez, R., \& Riquier, M. (1997). Test d'Acquisitions Scolaires Francais et mathematiques. CE1-CE2, CE2-CM1 [School Achievement Test: French and mathematics. CE1-CE2, CE2CM1]. Paris, France: ECPA.

McCloskey, M., Caramazza, A., \& Basili, A. (1985). Cognitive mechanisms in number processing and calculation: Evidence from discalculia. Brain and Cognition, 4, 171-196. http://dx.doi. org/10.1016/0278-2626(85)90069-7

O'Hare, A. E. (1999). Dysgraphia and dyscalculia. In K. Whltmore, H. Hart, \& G. Willems (Ed.), Clinics in Developmental Medicine (Vol. 145, pp. 96-118). London, England: Mac Keith Press.

Oliveira, M. S., \& Tourinho, E. Z. (2001). Desempenho de crianças do ensino fundamental na solução de problemas aritméticos [Performance of children of the elementary school in arithmetics problems solving]. Estudos de Psicologia, 6, 63-74. http://dx. doi.org/10.1590/S1413-294X2001000100007

Raad, A. J., Pimentel, C. E., \& Almeida, T. O. (2008). Avaliação neuropsicológica da aritmética em crianças [Neuropsychological evaluation of arithmetic in children]. Psicologia em Foco, 1, 1-13.

Rice, M. E., \& Harris, G. T. (2005). Comparing effect sizes in follow-up Studies: ROC Area, Cohen's d, and r. Law and human behavior, 29, 615-620. http://dx.doi.org/10.1007/ s10979-005-6832-7

Rosselli, M., Ardila, A., Matute, E., \& Inozemtseva, O. (2009). Gender differences and cognitive correlates of mathematical skills in school-aged children. Child Neuropsychology, 15, 216-231. http://dx.doi.org/10.1080/09297040802195205

Rotzer, S., Loenneker, T., Kucian, K., Martin, E., Klaver, P., \& von Aster, M. (2009). Dysfunctional neural network of spatial working memory contributes to developmental dyscalculia. Neuropsychologia, 47, 2859-2865. http://dx.doi.org/10.1016/j. neuropsychologia.2009.06.009

Santos, F. H., \& Bueno, O. F. A. (2003). Validation of the Brazilian Children's Test of pseudoword repetition in Portuguese speakers aged 4 to 10 years. Brazilian Journal of Medical and Biological Research, 36, 1533-1547. http://dx.doi.org/ 10.1590/S0100-879X2003001100012

Santos, F. H., Mello, C. B., Bueno, O. F. A., \& Dellatolas, G. (2005) Cross-cultural differences for three visual memory tasks in Brazilian children. Perceptual Motor Skills, 101, 421433. http://dx.doi.org/10.2466/pms.101.2.421-433

Santos, F. H., Paschoalini, B., \& Molina, J. (2006). Novos instrumentos para avaliação de habilidades matemáticas em crianças [New tools for assessment of mathematical skills in children]. In A. L. Sennyey, L. I. Z. Mendonça, B. B. G. Schlecht, E. F. Santos, \& E. C. Macedo (Org.), Neuropsicologia e inclusão [Neuropsychology and inclusion] (pp. 69-80). São Paulo, Brazil: Artes Médicas.

Santos, F. H., \& Silva, P. A. D. (2008). Avaliação da discalculia do desenvolvimento: Uma questão sobre o processamento numérico e o cálculo [Developmental dyscalculia assessment: A question of number processing and calculation]. In A. L. Senneyey, F. C. Capovilla, \& J. M. Montiel (Org.), Transtornos de aprendizagem: Da avaliação à reabilitação [Learning disorders: From assessment to rehabilitation] (pp. 125-137). São Paulo, Brazil: Artes Médicas.

Silva, P. A., \& Santos, F. H. (2009). Prejuízos específicos em habilidades matemáticas de crianças com transtornos de aprendizagem [Specific impairments of mathematic skill in children with learning disorders]. In J. M. Montiel \& F. C. Capovilla (Org.), Atualização em transtornos de aprendizagem [Updates on learning disorders] (pp. 57-71). São Paulo, Brazil: Artes Médicas.

Silva, P. A., \& Santos, F. H. (2011). Discalculia do desenvolvimento: Avaliação da representação numérica pela Zareki-R [Developmental dyscalculia: Assessment of number representation by the Zareki-R]. Psicologia: Teoria e Pesquisa, 27, 169-177. 
Shalev, R. S. (2004). Developmental dyscalculia. Journal of Child Neurology, 19, 765-771.

Shalev, R. S., Manor, O., Amir, N., \& Gross-Tsur, V. (1993). Acquisition of arithmetic in normal children: Assessment by a cognitive model of dyscalculia. Developmental Medicine \& Child Neurology, 35, 593-601. http://dx.doi.org/10.1111/j.14698749.1993.tb11696.x

Siegel, L. S., \& Ryan, E. B. (1989). The development of working memory in normally achieving and subtypes of learning disabled children. Child Development, 60, 973-980. http://dx. doi.org/10.2307/1131037

StatSoft, Inc. (1995). STATISTICA for Windows [Computer program manual]. Tulsa, OK: StatSoft, Inc.

Stein, L. M. (1994). TDE: Teste de Desempenho Escolar: Manual para aplicação e interpretação [TDE: School Achievent Test: Manual for application and interpretation]. São Paulo, Brazil: Casa do Psicólogo.

Swanson, H. L. (2006). Cognitive processes that underlie mathematical precociousness in young children. Journal of Experimental Child Psychology, 93, 239-264. http://dx.doi.org/ 10.1016/j.jecp.2005.09.006

von Aster, M. (1994). Developmental dyscalculia in children: Review of the literature and clinical validation. Acta Paedopsychiatrica, 56, 169-178.

von Aster, M. (2000). Developmental cognitive neuropsychology of number processing and calculation: Varieties of developmental dyscalculia. European Child and Adolescent Psychiatry, 9, 41-57. http://dx.doi.org/10.1007/s007870070008 von Aster, M. (2001). Die neuropsychologische Testbatterie für Zahlenverarbeitung und Rechnen bei Kindern (ZAREKI). [The neuropsychological test battery for number processing and calculation in children (NUCALC)]. Frankfurt, Germany: Swets \& Zeitliger.

von Aster, M., Deloche, G., Dellatolas, G., \& Meier, M. (1997). Number processing and calculation in 2nd and 3rd grade school children: A comparative study of French-speaking and Germanspeaking children. Zeitschrift fur Entwicklungspsychologie und padagogische Psychologie, 29, 151-166.

von Aster, M., \& Dellatolas, G. (2006). Zareki-R: Batterie pour l'évaluation du traitement des nombres et du calcul chez l'enfant. Adaptation Francaise [Zareki-R: Neuropsychological Test Battery for Number Processing and Calculation in Children. French adaptation]. Paris, France: ECPA.

von Aster, M., \& Shalev, R. S. (2007). Number development and developmental dyscalculia. Developmental Medicine \& Child Neurology, 49, 868-873. http://dx.doi.org/10.1111/j.14698749.2007.00868.x

von Aster, M. G., Weinhold Zulauf, M., \& Horn, R. (2006). Zareki$R$ Neuropsychologische Testbatterie für Zahlenverarbeitung und Rechnen bei Kindern [Neuropsychological Test Battery for Number Processing and Calculation in Children]. Frankfurt A.M., Germany: Harcourt Test Services.

Wechsler, D. (2002). WISC-III: Escala de Inteligência Wechsler para Crianças: Manual [WISC-III: Wechsler Intelligence Scale for Children: Manual] ( $3^{\text {rd }}$ Ed.). São Paulo, Brazil: Casa do Psicólogo.

Weinhold Zulauf, M., Schweiter, M., \& von Aster, M. G. (2003). Das Kindergartenalter: Sensitive periode für die entwicklung numerischer fertigkeiten [The preschool year: A sensitive period for the development of numerical abilities]. Kindheit und Entwicklung, 12, 222-230. http://dx.doi.org/10.1026//09425403.12.4.222

World Health Organization (2005). ICD-10. International statistical classification of diseases and related health problems. Chapter $\mathrm{V}$ : Mental and behavioural disorders (F81.2). Geneva, Switzerland: Author.

Received June 21, 2010

Revision received June 16, 2011

Accepted July 13, 2011 